\title{
Factors Affecting Sodium Reabsorption by the Proximal Tubule as Determined during Blockade of Distal Sodium Reabsorption *
}

\author{
Laurence E. Earley, $†$ Joseph A. Martino, and Robert M. Friedler \\ (From the Thorndike Memorial Laboratory, the Second and Fourth [Harvard] Medical \\ Services, Boston City Hospital, and the Department of Medicine, Harvard Medical \\ School, Boston, Mass.)
}

Changes in the tubular reabsorption of sodium independent of aldosterone activity may play an important role in determining sodium excretion. Several studies in the dog employing clearance techniques have demonstrated that infusions of isotonic saline (1-5) or plasma-like solutions (1, 2) result in a depression of the over-all net tubular reabsorption of sodium as the excretion of sodium increases. Dirks, Cirksena, and Berliner have demonstrated by micropuncture studies in the dog that this depression of tubular reabsorption during the infusion of saline occurs specifically in the proximal tubule (6). These same authors reported that acute constriction of the thoracic inferior vena cava, a maneuver known to inhibit sodium excretion and to lead to chronic sodium retention and the formation of ascites (7), prevents this depression of proximal reabsorption during saline infusion (8). Such studies indicate that nonaldosterone factors determining the rate of sodium reabsorption by the proximal tubule could play a major role in the normal physiologic regulation of sodium balance and also may be involved in the pathogenesis of sodium retention in disorders characterized by the accumulation of ascites and edema.

Although the factors that determine the rate of proximal tubular reabsorption are unknown, recent studies from our laboratory have demonstrated that renal vascular resistance and perfusion pressure may affect the over-all tubular reabsorp-

* Submitted for publication April 26, 1966; accepted July 21, 1966.

Aided in part by grants AM-5401-05 from the $\mathrm{Na}$ tional Institutes of Health and NsG595 from the $\mathrm{Na}$ tional Aeronautics and Space Administration.

$\dagger$ Address requests for reprints to Dr. Laurence $\mathrm{E}$. Earley, Thorndike Memorial Laboratory, Boston City Hospital, Boston, Mass. 02118. tion of sodium (9). Extension of these studies in dogs with caval constriction has indicated that increased arterial pressure in the presence of reduced renal vascular resistance decreases the net tubular reabsorption of sodium and may completely overcome the impaired response to saline infusion resulting from both acute and chronic constriction of the thoracic inferior vena cava (10). Such studies employing clearance techniques have not revealed whether these hemodynamically induced changes in the reabsorption of sodium occur in the proximal nephron, the site at which micropuncture studies indicate a depression in reabsorption in response to extracellular volume expansion, and an increased reabsorption in the presence of acute constriction of the thoracic inferior vena cava.

In the present series of studies we have attempted to examine some of the factors that may affect the reabsorption of sodium in the proximal tubule. In the presence of complete, or nearly complete, interference with sodium reabsorption in the distal nephron by natriuretic agents which appear to have little or no effect on the proximal reabsorption of sodium, it should be possible to observe the effects of other maneuvers that independently alter proximal reabsorption. Studies employing clearance techniques in the dog suggest that ethacrynic acid may completely abolish sodium reabsorption in the ascending limb of Henle's loop (11) and that chlorothiazide interferes with sodium reabsorption at an even more distal tubular site $(11,12)$. When given in combination during water diuresis, the two agents reduce free water clearance to less than $5 \%$ of the glomerular filtrate, and the excretion of sodium is increased to about $35 \%$ of the filtered load (11). These observations are consistent with the 
view that these diuretic agents in combination could block the major part of distal tubular reabsorption of sodium, since micropuncture studies in the hydropenic dog suggest that at least $65 \%$ of the filtered sodium is reabsorbed in the proximal nephron (13). Furthermore, Dirks and his associates have reported that neither ethacrynic acid nor chlorothiazide has any net effect on proximal reabsorption in the dog as determined by micropuncture of superficial nephrons (14). Thus, neither of these agents appears to affect net proximal tubular reabsorption of sodium, and in combination their effects on urinary dilution and fractional excretion of sodium suggest blockade of the major part of distal reabsorption.

In the present studies ethacrynic acid and chlorothiazide were infused together at rates known to produce maximal natriuretic effects, and urinary losses were replaced. In the presence of a steady state effect of the agents, we performed a number of different experiments to study the influence of other factors on sodium reabsorption. Under such conditions additional large changes in the tubular reabsorption of sodium may be attributable to changes in proximal reabsorption. The results demonstrate 1 ) that the infusion of isotonic saline results in both fractional and absolute decreases in sodium reabsorption, 2) that acute constriction of the thoracic inferior vena cava increases fractional sodium reabsorption, and 3 ) that this increased fractional reabsorption during acute caval constriction may be overcome by increasing arterial pressure. Furthermore, reduced renal perfusion pressure may increase fractional sodium reabsorption, but reduced filtration rate per se does not. In addition, an effect of oncotic pressure on sodium reabsorption has been demonstrated. Under the conditions of these experiments all of these effects may be attributed, at least in part, to changes in reabsorption by the proximal nephron.

\section{Methods}

Studies were carried out in 45 mongrel dogs of either sex, ranging in weight from 14 to $24 \mathrm{~kg}$. Animals were anesthetized with pentobarbital and ventilated through an endotracheal tube connected to a Harvard respirator. Each animal received an intramuscular injection of deoxycorticosterone acetate, $10 \mathrm{mg}$, and vasopressin, $5 \mathrm{U}$, approximately 3 hours before the experiment was begun. Ureters were cannulated through flank incisions with polyethylene tubing, and a plastic catheter was inserted into the left renal vein through the spermatic or ovarian vein. In 16 experiments a Blalock clamp was placed around the aorta (usually between the renal arteries), fixed to the body wall, and extended outward through a stab wound. In 17 experiments a 23-gauge needle connected to plastic tubing was inserted in the direction of flow into the left renal artery near its origin at the aorta. In six experiments a plastic tube containing steel wire was inserted around the thoracic inferior vena cava through a right thoracotomy and extended out the left side of the chest through a stab wound. The ends of this plastic tubing passed through a double-barreled rigid plastic sleeve, and the entire device permitted adjustable and reversible constriction of the inferior vena cava above the diaphragm and below the right atrium. Plastic catheters were inserted into a femoral artery and vein for measurements of aortic and inferior vena caval pressures with Sanborn pressure transducers and a model 964 recorder. Each animal received an intravenous infusion, which delivered inulin at the rate of 20 to $25 \mathrm{mg}$ per minute, $p$-aminohippurate (PAH) at 3.0 to $3.75 \mathrm{mg}$ per minute, deoxycorticosterone at 20 to $25 \mu \mathrm{g}$ per minute, and vasopressin at 40 to $50 \mathrm{mU}$ per $\mathrm{kg}$ per hour. This infusion was begun approximately 2 hours before experimental measurements.

Clearance periods were usually 5 minutes, and arterial and renal venous blood samples were collected at the midpoint of alternate periods, except during prediuretic control periods, which were longer, and when blood samples were collected with each clearance period. After 1 to 5 control collections, each animal received an intravenous injection of $50 \mathrm{mg}$ of ethacrynic acid ${ }^{1}$ and $250 \mathrm{mg}$ of chlorothiazide. 1 These were then infused at 40 and 200 $\mathrm{mg}$, respectively, per hour throughout the remainder of the experiment. Increased urine flow began within 60 seconds after the diuretic agents had been injected, and when a total urine volume of 75 to $100 \mathrm{ml}$ had been collected intravenous replacement was begun with a solution containing $\mathrm{Na} 145, \mathrm{~K} 4.5, \mathrm{Cl} 129.5$, and $\mathrm{HCO}_{3}, 20 \mathrm{mEq}$ per L. This solution was infused at a rate approximately 2 $\mathrm{ml}$ per minute less. than the total rate of urine flow and was increased as urine flow increased during the first 30 minutes after infusion of diuretics was begun. Afterwards, the rate of infusion of this replacement solution was kept constant, and another 30 minutes was allowed for urine flow to stabilize. This procedure resulted in negative volume balances ranging from 250 to $500 \mathrm{ml}$ by the time experimental collections were begun. One hour after infusion of ethacrynic acid and chlorothiazide was begun, when urine flow and plasma inulin, PAH, and sodium concentrations were stable, three to seven clearance periods were collected. Experiments were then continued according to one of the following protocols. The infusion of the replacement solution was continued unin-

1 Ethacrynic acid and chlorothiazide were kindly supplied for use in these studies by Dr. William $\mathrm{H}$. Wilkinson of Merck Sharp \& Dohme Research Laboratories, West Point, $\mathrm{Pa}$. 
terrupted and independent of any of the procedures described below.

Saline loading. In 18 experiments after collections during a steady state of drug-induced diuresis and replacement of urinary losses (hydropenia) the animals received an infusion of 500 or $600 \mathrm{ml}$ of Ringer's solution (the same solution described above for replacement of urinary losses, and hereafter referred to as saline) at 30 $\mathrm{ml}$ per minute, which afterwards was continued at $10 \mathrm{ml}$ per minute. Further clearance periods were collected 40 to 60 minutes after the saline infusion was begun, when plasma concentrations of inulin and PAH were stable. In 16 of these experiments we constricted the aorta between the renal arteries to reduce glomerular filtration rate by the left kidney 5 to $59 \%$. Collections during aortic constriction were made before the infusion of saline in nine experiments, and during saline infusion in 14 experiments. In seven experiments norepinephrine was infused into the left renal artery both before and after saline loading at rates (2.0 to $12.5 \mu \mathrm{g}$ per minute) producing a 10 to $58 \%$ reduction in glomerular filtration rate by the left kidney.

Pressor infusions. In ten experiments after collections during the steady state diuretic phase angiotensin (5 to $50 \mu \mathrm{g}$ per minute) or norepinephrine ( $50 \mu \mathrm{g}$ per minute) was infused intravenously to produce increases in arterial pressure ranging from 5 to $89 \mathrm{~mm} \mathrm{Hg}$. Further collections were made during the period of elevated arterial pressure. In nine of these observations an infusion of acetylcholine into the left renal artery at 10 to $40 \mu \mathrm{g}$ per minute was begun before infusion of angiotensin intravenously, and collections were made during renal vasodilatation before and during the period of increased arterial pressure.

Albumin infusions. In eight of the experiments described in the first protocol (saline loading), an infusion of $30 \mathrm{~g}$ per $100 \mathrm{ml}$ bovine albumin in isotonic saline was begun intravenously at $5 \mathrm{ml}$ per minute and continued until a total of $75 \mathrm{~g}$ of albumin was infused. This infusion of albumin was begun after collections during the stable natriuresis produced by the saline load. Collections were made at 5 - to 10 -minute intervals after the infusion of albumin was begun, and they continued for 10 to 30 minutes after this infusion was completed. During the infusion of albumin the saline infusion was slowed from 10 to $6.25 \mathrm{ml}$ per minute $(5 \mathrm{ml}$ of the albumin solution contains $3.75 \mathrm{ml}$ saline).

In five experiments after collections during the steady state diuretic phase (hydropenia), an infusion of $6.5 \%$ bovine albumin in isotonic saline was begun at $30 \mathrm{ml}$ per minute. After 300 to $400 \mathrm{ml}$ was infused, the rate was decreased to $5 \mathrm{ml}$ per minute. When a total of 600 to $800 \mathrm{ml}$ of this $6.5 \%$ albumin solution had been infused, further collections were made. In two of these experiments the aorta was then constricted to reduce mean aortic pressure to the same level as that present before

TABLE I

The effects of saline infusion and aortic constriction on fractional sodium reabsorption during distal tubular blockade*

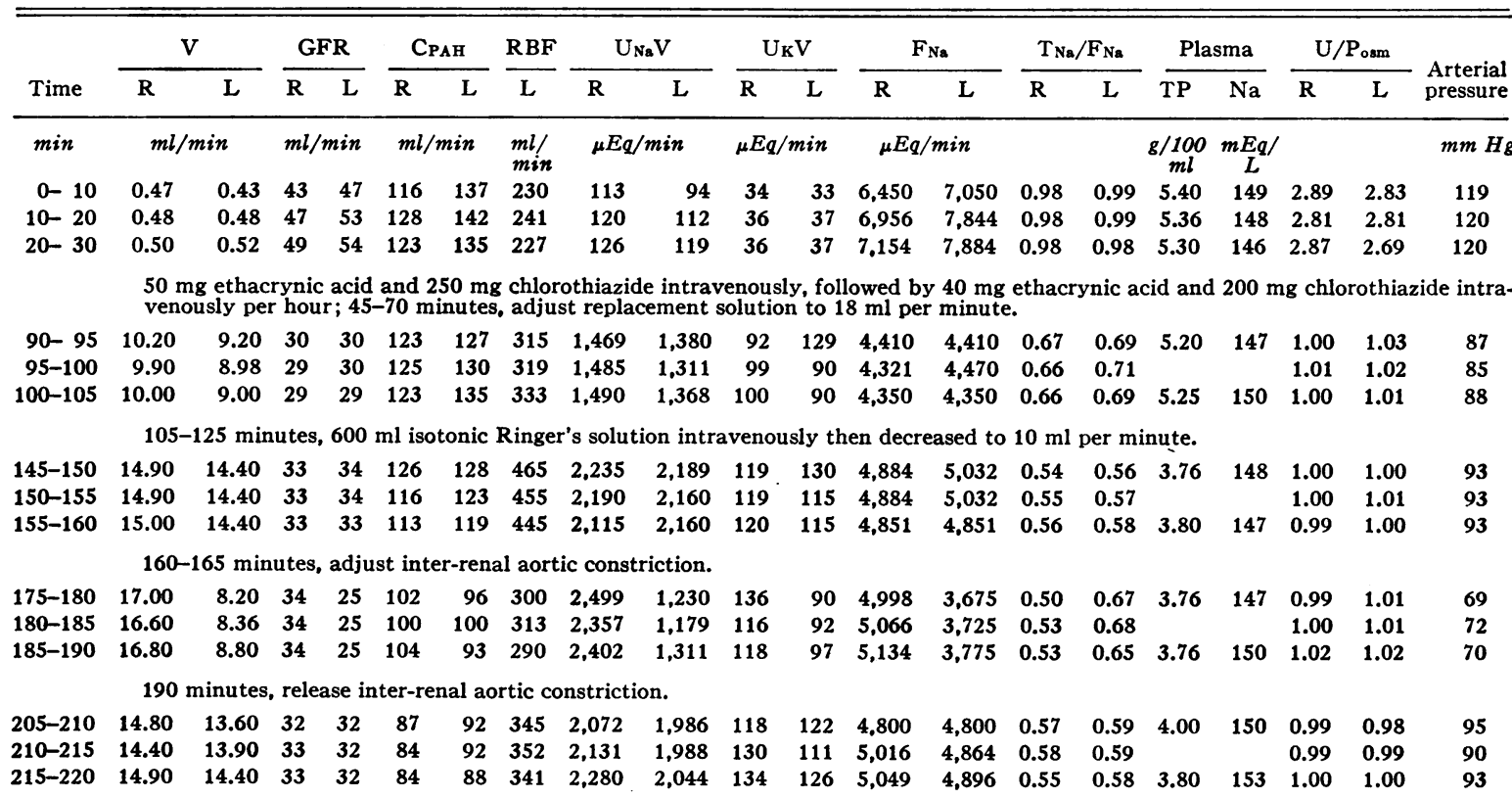

* Transitional periods between phases of the experiments have been omitted from all of the Tables. Abbreviations are as follows: $\mathrm{V}=$ rate of urine flow; $R=$ right $;==$ left $; G F R=$ glomerular filtration rate (the clearance of inulin); $C_{P A B}=$ clearance of $p$-aminohippurate; $R B F=$ total renal blood flow; $U_{\mathrm{Na}}=$ rate of excretion of sodium; $U_{\mathbf{K V}}=$ rate of excretion of potassium; $F_{\mathrm{Na}}=$ rate of filtration of sodium $[\mathrm{GFR} \times$ concen tration of $\mathrm{Na}$ in plasma $\left.\left(\mathrm{P}_{\mathrm{Na}}\right)\right]$; $\mathrm{T}_{\mathrm{Na}}=$ rate of tubular reabsorption of sodium $\left(\mathrm{F}_{\mathrm{Na}}-\mathrm{U}_{\mathrm{NaV}}\right) ; \mathrm{T}_{\mathrm{Na}} / \mathrm{F}_{\mathrm{Na}}=$ fraction of filtered sodium reabsorbed; $\mathrm{TP}=$ total protein concentration; $\mathrm{U} / \mathrm{P}_{\mathrm{Oam}}=$ ratio of urinary to plasma osmolality. 
TABLE II

Comparison of the effects of aortic constriction and the renal arterial infusion of norepinephrine on fractional sodium reabsorption during distal tubular blockade*

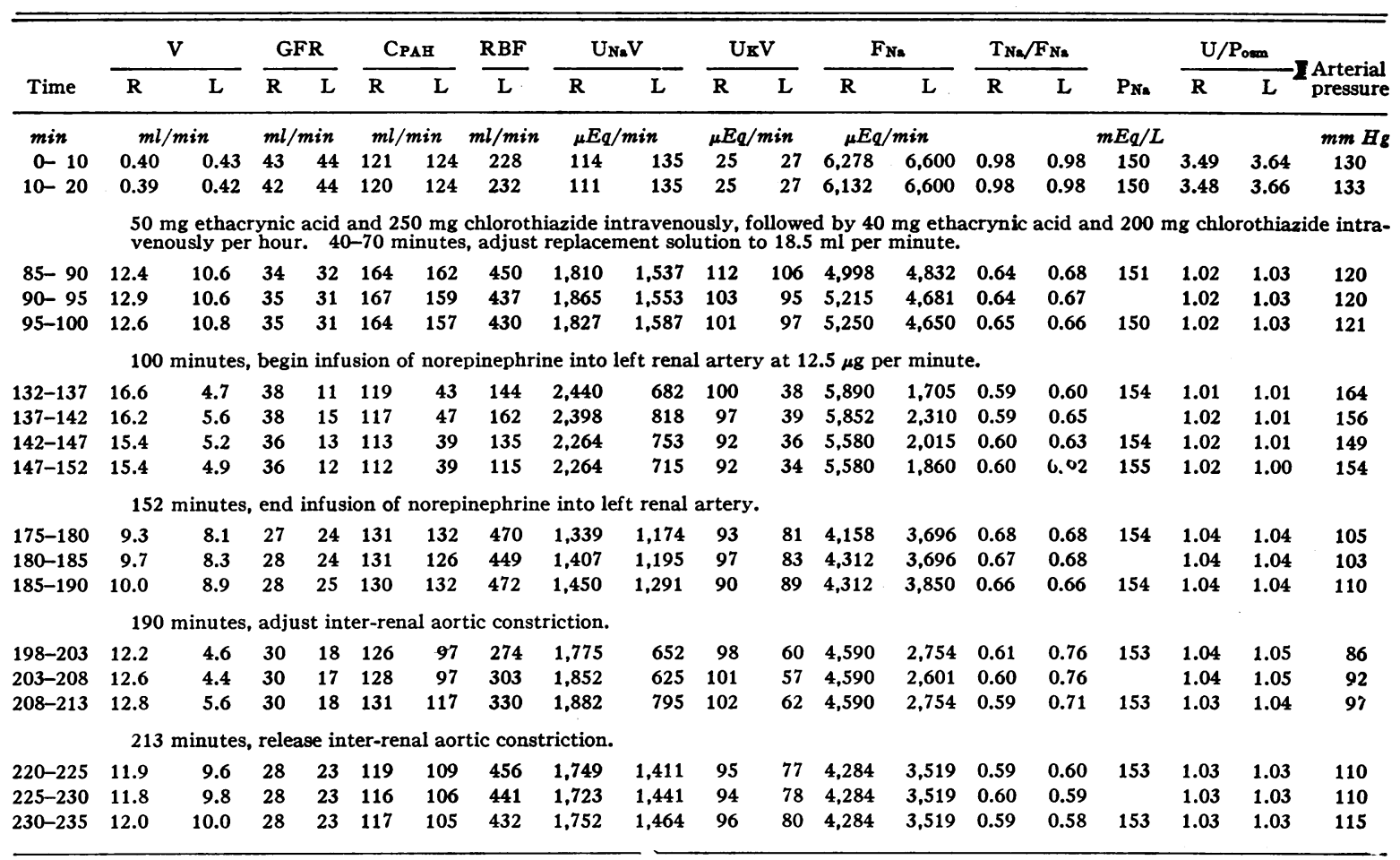

* Abbreviations are the same as in Table $\mathrm{I}$.

the infusion. After additional collections the aortic constriction was removed. To minimize the effects of large increases in renal blood flow (RBF) that occurred during the infusions of protein-containing solutions, we produced unilateral renal vasodilatation in two of these experiments by infusing acetylcholine ( $40 \mu \mathrm{g}$ per minute) into the renal artery before infusion of the $6.5 \%$ albumin.

Constriction of the thoracic inferior vena cava. In six experiments after collections during the steady state diuretic phase the thoracic inferior vena cava was constricted to produce a venous pressure of 15 to $28 \mathrm{~mm}$ $\mathrm{Hg}$. At the same time an infusion of saline was begun at $30 \mathrm{ml}$ per minute and after 20 minutes decreased to $10 \mathrm{ml}$ per minute. One hour after constricting the vena cava and beginning the infusion of saline, we again made collections. Arterial pressure was then increased by the intravenous infusion of angiotensin (3.25 to $10.0 \mu \mathrm{g}$ per minute) to an average of $52 \mathrm{~mm} \mathrm{Hg}$ above the caval constriction values. After collections during the infusion of angiotensin the agent was discontinued and arterial pressure allowed to decrease. Norepinephrine ( 9.0 to $50 \mu \mathrm{g}$ per minute) was then infused to achieve a similar elevation of arterial pressure, and further collections were made. Finally, after additional collections following the infusion of norepinephrine, the constriction of the inferior vena cava was removed.
Inulin, PAH, osmolality, sodium, and potassium were determined by methods previously described for this laboratory (15). Total protein in plasma was determined by a modified biuret method (16), and hematocrits (Hct) were determined in standard Wintrobe tubes. Renal plasma flow (RPF) was calculated by the formula of Wolf (17) : $R P F=[V(U-R)]^{2} /(A-R)$, where $V=$ rate of urine flow and $U$ urinary, $R$ renal venous, and $A$ arterial, concentration of PAH. Renal blood flow (RBF) $=\mathrm{RPF} /(1-.95 \mathrm{Hct})$. Renal vascular resistance was calculated in peripheral resistance units (PRU) froin RBF, arterial pressure $(\mathrm{Pa})$, and venous pressure $(\mathrm{Pv})$ : $\mathrm{PRU}=\left(\mathrm{Fa}_{\mathrm{a}}-\mathrm{Pv}\right) / \mathrm{RBF}$.

\section{Results}

Effects of combined ethacrynic acid and chlorothiazide. Before we infused the combination of

2 During the infusion of ethacrynic acid and chlorothiazide the extraction ratio (E) for $\mathrm{PAH}$ was as low as 0.25 , and urine volumes avuraged about $35 \%$ of the glomerular filtrate. Therefore, a considerable error would be introduced if RPF were calculated from the simpler formula, $R P F=C_{P A B} / E_{P A B}$, where $C=$ clearance. The reason for such low values for $E_{P A B}$ is not clear; but could result in part from the direct competition for excretion between PAH and chlorothiazide (18). 
TABLE III

Effects of saline loading, unilateral renal arterial infusion of norepinephrine, and systemic infusion of hyperoncotic albumin on fractional sodium reabsorption during distal tubular blockade*

\begin{tabular}{|c|c|c|c|c|c|c|c|c|c|c|c|c|c|c|c|c|c|c|c|}
\hline \multirow[b]{2}{*}{ Time } & \multicolumn{2}{|c|}{ V } & \multicolumn{2}{|c|}{ GFR } & \multicolumn{2}{|c|}{ CPAH } & \multirow{2}{*}{$\frac{\mathrm{RBF}}{\mathrm{L}}$} & \multicolumn{2}{|c|}{$\mathrm{UNaV}_{\mathrm{Na}}$} & \multicolumn{2}{|c|}{$\mathrm{UKV}_{\mathrm{K}}$} & \multicolumn{2}{|c|}{$F_{\mathrm{Na}}$} & \multicolumn{2}{|c|}{$\mathrm{T}_{\mathrm{Na}} / \mathrm{F}_{\mathrm{Na}}$} & \multicolumn{2}{|c|}{ Plasma } & \multirow{2}{*}{$\frac{U / P_{\text {osm }}}{L}$} & \multirow{2}{*}{$\begin{array}{l}\text { Arteria } \\
\text { pressur }\end{array}$} \\
\hline & $\mathbf{R}$ & L & $\mathbf{R}$ & L & $\mathbf{R}$ & L & & $\mathbf{R}$ & $\mathbf{L}$ & $\mathbf{R}$ & $\mathbf{L}$ & $\mathbf{R}$ & $\mathbf{L}$ & $\mathbf{R}$ & $\mathbf{L}$ & $\mathrm{TP}$ & $\mathrm{Na}$ & & \\
\hline $\min$ & \multicolumn{2}{|c|}{$\mathrm{ml} / \mathrm{min}$} & \multicolumn{2}{|c|}{$m l / m i n$} & \multicolumn{2}{|c|}{$\mathrm{ml} / \mathrm{min}$} & \multirow{2}{*}{$\begin{array}{c}m l / \min \\
193\end{array}$} & \multicolumn{2}{|c|}{$\mu E q / \min$} & \multicolumn{2}{|c|}{$\mu E q / \min$} & \multicolumn{2}{|c|}{$\mu E q / \min$} & & & $g / 100$ & $n E q / L$ & & $m m H_{\varepsilon}$ \\
\hline $0-30$ & 0.18 & 0.15 & 47 & 41 & 134 & 122 & & 44 & 30 & 24 & 20 & 7,191 & 6,273 & 0.99 & 0.99 & 5.64 & 153 & 4.59 & 136 \\
\hline & $\begin{array}{l}50 \mathrm{n} \\
\text { ven }\end{array}$ & sly p & & & & & 1 & id & & $\because$ & & & 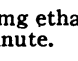 & & & & & & \\
\hline $90-95$ & 12.20 & 11.10 & 32 & 29 & 77 & 70 & 329 & 1,671 & 1,542 & 122 & 111 & 4,928 & 4,350 & 0.66 & 0.65 & 5.98 & 154 & 0.99 & 137 \\
\hline $95-100$ & 11.84 & 11.00 & 31 & 28 & 71 & 66 & 299 & 1,634 & 1,529 & 118 & 110 & 4,681 & 4,200 & 0.65 & 0.64 & & & 1.00 & 130 \\
\hline $100-105$ & 11.70 & 10.90 & 31 & 28 & 70 & 62 & 275 & 1,591 & 1,515 & 117 & 109 & 4,557 & 4,200 & 0.65 & 0.64 & 5.94 & 148 & 1.01 & 130 \\
\hline & 105 & $5 \mathrm{mi}$ & ate & 00 & is & ic $\mathbf{F}$ & inger's & olutio & itraven & ously & hen & decrease & 1 to 10 & nl per & ninute & & & & \\
\hline $140-145$ & 18.40 & 16.30 & 36 & 33 & 57 & 52 & 349 & 2,489 & 2,266 & 146 & 130 & 5,400 & 4,950 & 0.57 & 0.54 & 4.76 & 150 & 1.00 & 146 \\
\hline $145-150$ & 17.84 & 16.20 & 35 & 32 & 57 & 52 & 349 & 2,426 & 2,219 & 142 & 130 & 5,180 & 4,736 & 0.53 & 0.53 & & & 1.01 & 145 \\
\hline $150-155$ & 17.90 & 16.00 & 35 & 31 & 54 & 49 & 319 & 2,399 & 2,224 & 143 & 128 & 5,075 & 4,526 & 0.53 & 0.51 & 4.85 & 145 & 1.00 & 146 \\
\hline & 155 & nute & & 11 & 101 & nor & inepn & ine in & 21 & al art & at & $\rho \mu \mathrm{g}$ & ninute & & & & & & \\
\hline $168-173$ & 21.40 & 11.50 & 41 & 25 & 53 & 34 & 170 & 2,825 & 1,564 & 171 & 92 & 5,945 & 3,625 & 0.52 & 0.56 & 4.92 & 145 & 1.00 & 193 \\
\hline $173-178$ & 21.20 & 11.00 & 40 & 24 & 52 & 33 & 172 & 2,820 & 1,485 & 191 & 88 & 5,840 & 3,504 & 0.52 & 0.58 & & & 1.00 & 181 \\
\hline $178-183$ & 21.00 & 11.00 & 40 & 24 & 49 & 31 & 164 & 2,814 & 1,485 & 189 & 88 & 5,840 & 3,504 & 0.52 & 0.58 & 4.86 & 146 & 1.00 & 185 \\
\hline $183-188$ & 21.20 & 10.20 & 40 & 20 & 50 & 29 & 168 & 2,841 & 1,377 & 191 & 82 & 5,840 & 2,920 & 0.51 & 0.53 & & & 1.00 & 178 \\
\hline $188-193$ & 21.20 & 9.80 & 39 & 20 & 49 & 25 & 156 & 2,820 & 1,333 & 191 & 78 & 5,694 & 2,920 & 0.50 & 0.53 & 4.69 & 146 & 1.00 & 185 \\
\hline & 193 & ite & & & & arte & al inf & sion $\mathrm{c}$ & epin & phrin & & & & & & & & & \\
\hline $216-221$ & 15.20 & 12.80 & 32 & 28 & 41 & 37 & 307 & 2,052 & 1,741 & 152 & 128 & 4,640 & 4,060 & 0.56 & 0.57 & 4.02 & 145 & 1.00 & 133 \\
\hline $221-226$ & 14.40 & 12.30 & 30 & 25 & 41 & 37 & 283 & 1,958 & 1,694 & 144 & 123 & 4,410 & 3,675 & 0.56 & 0.54 & & & 1.00 & 121 \\
\hline $226-231$ & 14.30 & 12.30 & 29 & 27 & 43 & 39 & 274 & 1,945 & 1,710 & 157 & 135 & 4,321 & 4,023 & 0.55 & 0.57 & 3.78 & 149 & 1.00 & 117 \\
\hline $231-236$ & 14.50 & 12.40 & 31 & 27 & 49 & 47 & 355 & 1,972 & 1,724 & 160 & 136 & 4,650 & 4,050 & 0.58 & 0.57 & & & 1.00 & 117 \\
\hline $236-241$ & 14.40 & 12.30 & 30 & 25 & 48 & 45 & 353 & 1,944 & 1,685 & 158 & 135 & 4,500 & 3,750 & 0.57 & 0.55 & 3.58 & 150 & 1.00 & 119 \\
\hline & 241 & inutes, & eg & int & ven & infu & ion of & $30 \mathrm{~g} \mathrm{pe}$ & $100 \mathrm{ml}$ & bovir & albs & $\min$ in $i$ & tonic & Ringer & solut & n & $n$ & minute. & \\
\hline $241-251$ & 14.50 & 12.40 & 30 & 27 & 47 & 44 & 341 & 1,987 & 1,736 & 160 & 136 & 4,500 & 4,050 & 0.56 & 0.57 & & & 1.01 & 129 \\
\hline $251-257$ & 13.08 & 10.50 & 29 & 26 & 50 & 45 & 335 & 1,779 & 1,449 & 157 & 126 & 4,379 & 3,926 & 0.59 & 0.63 & 4.32 & 150 & 1.01 & 129 \\
\hline $257-261$ & 11.50 & 9.80 & 28 & 25 & 49 & 47 & 344 & 1,587 & 1,362 & 150 & 118 & 4,256 & 3,775 & 0.63 & 0.64 & & & 1.01 & 125 \\
\hline $261-266$ & 12.20 & 9.96 & 30 & 26 & 58 & 52 & 383 & 1,671 & 1,374 & 159 & 129 & 4,560 & 3,952 & 0.63 & 0.65 & 4.92 & 152 & 1.01 & 125 \\
\hline $266-271$ & 11.50 & 9.50 & 29 & 25 & 51 & 48 & 284 & 1,564 & 1,273 & 150 & 124 & 4,408 & 3,800 & 0.65 & 0.66 & & & 1.01 & 134 \\
\hline $271-276$ & 10.10 & 9.70 & 28 & 28 & 51 & 54 & 244 & 1,364 & 1,300 & 152 & 136 & 4,256 & 4,256 & 0.68 & 0.69 & 5.53 & 152 & 1.01 & 127 \\
\hline $276-281$ & 9.40 & 7.80 & 28 & 24 & 54 & 48 & 206 & 1,260 & 1,037 & 150 & 117 & 4,256 & 3,648 & 0.70 & 0.72 & & & 1.01 & 122 \\
\hline $281-286$ & 8.80 & 7.40 & 27 & 24 & 55 & 51 & 201 & 1,179 & 999 & 150 & 126 & 4,077 & 3,624 & 0.71 & 0.72 & 5.64 & 151 & 1.01 & 122 \\
\hline $286-294$ & 8.37 & 6.87 & 27 & 23 & 64 & 58 & 243 & 1,130 & 907 & 151 & 117 & 4,131 & 3,519 & 0.73 & 0.74 & 5.74 & 153 & 1.01 & 122 \\
\hline & 294 & nutes, & end & Con & M & sion. & & & & & & & & & & & & & \\
\hline 294-299 & 8.70 & 7.20 & 30 & 25 & 67 & 62 & 303 & 1,166 & 986 & 157 & 130 & 4,560 & 3,800 & 0.74 & 0.74 & & & 1.01 & 126 \\
\hline 299-304 & 9.10 & 7.50 & 31 & 25 & 71 & 65 & 330 & 1,219 & 1,013 & 164 & 128 & 4,712 & 3,800 & 0.74 & 0.73 & 5.42 & 152 & 1.01 & 125 \\
\hline $304-309$ & 9.80 & 8.10 & 30 & 26 & 74 & 69 & 321 & 1,313 & 1,110 & 176 & 138 & 4,560 & 3,952 & 0.71 & 0.72 & & & 1.00 & 125 \\
\hline $309-314$ & 10.40 & 8.56 & 30 & 26 & 75 & 68 & 321 & 1,404 & 1,173 & 176 & 146 & 4,560 & 3,952 & 0.69 & 0.70 & 5.11 & 152 & 1.01 & 130 \\
\hline $314-319$ & 11.00 & 9.00 & 31 & 27 & 83 & 76 & 375 & 1,496 & 1,215 & 187 & 144 & 4,712 & 4,104 & 0.68 & 0.70 & & & 1.00 & 130 \\
\hline $319-324$ & 11.40 & 9.20 & 32 & 26 & 82 & 75 & 387 & 1,539 & 1,242 & 182 & 138 & 4,864 & 3,952 & 0.68 & 0.69 & 4.95 & 152 & 1.00 & 135 \\
\hline
\end{tabular}

* Abbreviations are the same as in preceding tables.

diuretic agents, glomerular filtration rate (GFR) averaged $39 \mathrm{ml}$ per minute per kidney, RBF averaged $195 \mathrm{ml}$ per minute per kidney, and arterial pressure averaged $133 \mathrm{~mm} \mathrm{Hg}$. The fractional reabsorption of sodium averaged 0.98 , and urinary osmolality ranged from 418 to 2,344 (average 1,046) mOsm per kg. During the steady state of diuretic infusion and replacement of urinary losses GFR was reduced by an average of $28 \%$, and RBF was increased strikingly by an average of $49 \%$, despite an average decrease of $19 \mathrm{~mm} \mathrm{Hg}$ in arterial pressure. Thus, the diuretic agents resulted in marked renal vasodilatation with a reduction in average renal vascular resistance from 0.73 to $0.47 \mathrm{PRU}$. Urinary total solute concentration was reduced to isotonicity in all experiments, and urinary/plasma (U/P) osmolality remained virtually at unity throughout all studies, despite the reductions in GFR and urine flow induced by some of the maneuvers (Tables I-IV). During the steady state (infusion of drugs and replacement of urinary losses) the fraction of fil- 
TABLE IV

The effect of thoracic vena caval constriction of preventing depression of fractional sodium reabsorption during saline infusion and reversal of this effect during infusions of pressor agents, as studied during distal tubular blockade*

\begin{tabular}{|c|c|c|c|c|c|c|c|c|c|c|c|c|c|c|c|c|c|c|c|c|}
\hline \multirow[b]{2}{*}{ Time } & \multicolumn{2}{|c|}{$\mathrm{V}$} & \multicolumn{2}{|c|}{$\underline{\text { GFR }}$} & \multicolumn{2}{|c|}{ CPAE } & \multirow{2}{*}{$\frac{\text { RBF }}{L}$} & \multicolumn{2}{|c|}{$\mathrm{UNaV}_{\mathrm{Na}}$} & \multicolumn{2}{|c|}{ UKV } & \multicolumn{2}{|c|}{$\mathrm{F}_{\mathrm{Na}}$} & \multicolumn{2}{|c|}{$\mathrm{T}_{\mathrm{Na}} / \mathrm{F}_{\mathrm{Na}}$} & \multirow[b]{2}{*}{$P_{N a}$} & \multicolumn{2}{|c|}{$\mathrm{U} / \mathrm{P}_{\text {osm }}$} & \multirow{2}{*}{$\begin{array}{l}\text { Arterial } \\
\text { pressure }\end{array}$} & \multirow{2}{*}{$\begin{array}{l}\text { Venous } \\
\text { pressure }\end{array}$} \\
\hline & $\mathbf{R}$ & L & $\mathbf{R}$ & L & $\mathbf{R}$ & $\mathbf{L}$ & & $\mathbf{R}$ & L & $\mathbf{R}$ & $\mathbf{L}$ & $\mathbf{R}$ & $\mathbf{L}$ & $\mathbf{R}$ & $\mathbf{L}$ & & $\mathbf{R}$ & L & & \\
\hline $\min$ & \multicolumn{2}{|c|}{$m l / m i n$} & \multicolumn{2}{|c|}{$m l / m i n$} & \multicolumn{2}{|c|}{$m l / m i n$} & \multirow{2}{*}{$\begin{array}{c}m l / \\
\text { min } \\
196\end{array}$} & \multicolumn{2}{|c|}{$\mu E q / \min$} & \multicolumn{2}{|c|}{$\mu E q / \min$} & \multicolumn{2}{|c|}{$\mu E q / \min$} & & & $m E q / L$ & & & & $n \boldsymbol{H g}$ \\
\hline $0-10$ & 0.39 & 0.44 & 22 & 25 & 86 & 92 & & 77 & 84 & 19 & 21 & 3,300 & 3,750 & 0.98 & 0.98 & 150 & 2.29 & 2.22 & 128 & 6 \\
\hline $10-20$ & 0.39 & 0.43 & 24 & 25 & 97 & 86 & 186 & 74 & 79 & 20 & 22 & 3,600 & 3,750 & 0.98 & 0.98 & 150 & 2.34 & 2.26 & 125 & 6 \\
\hline & $\begin{array}{l}50 \mathrm{n} \\
\text { ven }\end{array}$ & etha & cryn & $c a$ & & & $\mathrm{mg}$ & protl & de & av & & foll & ed by & $\mathrm{m}$ & ethac & c ac & nd 200 & $\mathrm{mg}$ & orothi & de int \\
\hline $75-80$ & 6.56 & 6.80 & 21 & 22 & 82 & 87 & 231 & 911 & 972 & 59 & 61 & 3,213 & 3,366 & 0.72 & 0.71 & 153 & 1.00 & 1.01 & 113 & 6 \\
\hline $80-85$ & 6.62 & 6.60 & 21 & 22 & & 84 & 223 & 927 & 944 & 60 & 59 & 3,213 & 3,366 & 0.71 & 0.72 & & 1.00 & 1.01 & 111 & 5 \\
\hline $85-90$ & 6.60 & 6.78 & 21 & 22 & 87 & 87 & 233 & 924 & 970 & 59 & 61 & 3,192 & 3,344 & 0.71 & 0.71 & 152 & 0.98 & 1.01 & 113 & 5 \\
\hline & $\begin{array}{l}91-1 \\
94-1\end{array}$ & & & ad & & rara & & r's so & aval & & & & decta & & $10 \mathrm{ml}$ & & & & & \\
\hline $157-162$ & 4.16 & 3.50 & 14 & 13 & 55 & 55 & 136 & 578 & 494 & 46 & 42 & 2,142 & 1,989 & 0.73 & 0.75 & 153 & 1.00 & 1.01 & 81 & 20 \\
\hline $162-167$ & 3.48 & 2.88 & 12 & 11 & 48 & 45 & 112 & 480 & 403 & 42 & 40 & 1,836 & 1,683 & 0.74 & 0.76 & & 1.00 & 1.01 & 78 & 21. \\
\hline $167-172$ & 3.14 & 2.78 & 11 & 11 & 45 & 47 & 120 & 436 & 389 & 38 & 36 & 1,672 & 1,672 & 0.74 & 0.77 & 152 & 1.00 & 1.01 & 76 & 21 \\
\hline $172-177$ & 3.13 & 2.62 & 12 & 11 & 49 & 42 & 111 & 435 & 367 & 38 & 37 & 1,836 & 1,683 & 0.76 & 0.78 & & 1.00 & 1.00 & 72 & 22 \\
\hline $177-182$ & 3.20 & 2.78 & 12 & 12 & 51 & 51 & 142 & 445 & 392 & 38 & 36 & 1,836 & 1,836 & 0.76 & 0.77 & 153 & 0.99 & 1.00 & 72 & 23 \\
\hline & 182 & minute & s, beg & $\sin$ ir & atrav & enou & is infu & ion of a & ngioten & isin at & $5 \mu \mathrm{g}$ & per min & nute. & & & & & & & \\
\hline $190-195$ & 10.86 & 10.80 & 23 & 23 & 59 & 60 & 208 & 1,553 & 1,555 & 76 & 86 & 3,519 & 3,519 & 0.56 & 0.56 & 153 & 0.97 & 0.99 & 143 & 24 \\
\hline $195-200$ & 10.60 & 10.80 & 23 & 24 & 58 & 63 & 200 & 1,473 & 1,566 & 74 & 76 & 3,519 & 3,672 & 0.58 & 0.57 & 153 & 0.96 & 0.97 & 149 & 27 \\
\hline $200-205$ & 11.00 & 11.24 & 24 & 24 & 60 & 61 & 197 & 1,529 & 1,641 & 77 & 79 & 3,672 & 3,672 & 0.58 & 0.55 & & 0.97 & 0.97 & 146 & 20 \\
\hline $205-210$ & 10.80 & 11.00 & 24 & 24 & 61 & 55 & 175 & 1,512 & 1,606 & 65 & 77 & 3,672 & 3,672 & 0.59 & 0.56 & 153 & 0.97 & 0.98 & 148 & 21 \\
\hline & 210 & minutes & s, disc & conti & inue $i$ & infus & sion of & angiote & nsin. & & & & & & & & & & & \\
\hline $228-233$ & 4.30 & 3.72 & 15 & 15 & 44 & 46 & 143 & 589 & 528 & 39 & 37 & 2,295 & 2,295 & 0.74 & 0.77 & 153 & 1.00 & 1.00 & 78 & 21 \\
\hline $233-238$ & 4.40 & 3.76 & 15 & 15 & 46 & 46 & 149 & 607 & 534 & 40 & 38 & 2,295 & 2,295 & 0.74 & 0.77 & & 1.00 & 1.00 & 78 & 21 \\
\hline $238-243$ & 4.62 & 4.00 & 15 & 16 & 45 & 47 & 156 & 633 & 572 & 42 & 40 & 2,295 & 2,448 & 0.73 & 0.77 & 153 & 1.00 & 1.01 & 78 & 21 \\
\hline & 243 & 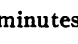 & s, beg & gin in & atrav & renou & is infu & n of $n$ & lorepine & ephrin & e at 1 & ms pe & minut & & & & & & & \\
\hline 249-254 & 11.30 & 11.86 & 24 & 26 & 56 & 61 & 297 & 1,571 & 1,720 & 79 & 83 & 3,672 & 3,978 & 0.57 & 0.57 & 153 & 0.98 & 0.98 & 115 & 21 \\
\hline 254-259 & 12.76 & 13.00 & 26 & 28 & 60 & 59 & 298 & 1,786 & 1,898 & 77 & 91 & 3,978 & 4,284 & 0.55 & 0.56 & & 0.98 & 0.99 & 118 & 21 \\
\hline 259-264 & 13.36 & 13.70 & 26 & 26 & 56 & 62 & 276 & 1,870 & 2,000 & 80 & 96 & 3,978 & 4,131 & 0.53 & 0.52 & 153 & 0.98 & 0.99 & 120 & 20 \\
\hline $264-269$ & 13.70 & 14.40 & 27 & 29 & 55 & 59 & 248 & 1,904 & 2,102 & 82 & 86 & 4,131 & 4,437 & 0.54 & 0.53 & & 1.00 & 0.99 & 115 & 20 \\
\hline $269-274$ & 14.10 & 14.90 & 28 & 30 & 55 & 63 & 264 & 1,974 & 2,175 & 85 & 89 & 4,256 & 4,560 & 0.54 & 0.52 & 152 & 1.00 & 0.99 & 114 & 20 \\
\hline & 274 & sinces & S, Cis & conti & inue & thos & sion o & . & cpinitic & & & & & & & & & & & \\
\hline $315-320$ & 11.30 & 11.30 & 25 & 25 & 58 & 60 & 245 & 1,559 & 1,627 & 90 & 90 & 3,825 & 3,825 & 0.59 & 0.57 & 153 & 0.99 & 0.99 & 97 & 19 \\
\hline $320-325$ & 11.70 & 11.60 & 25 & 25 & 61 & 60 & 237 & 1,615 & 1,636 & 94 & 93 & 3,825 & 3,825 & 0.58 & 0.57 & & 0.99 & 1.00 & 100 & 19 \\
\hline $325-330$ & 12.00 & 11.90 & 25 & 26 & 59 & 66 & 262 & 1,668 & 1,690 & 96 & 95 & 3,825 & 3,978 & 0.57 & 0.57 & 153 & 0.99 & 0.98 & 99 & 19 \\
\hline & & ninutes & 8, fen & hove & thor & . & fe & vena & aval c & onstr & tion. & & & & & & & & & \\
\hline $345-350$ & 16.50 & 16.70 & 34 & 34 & 73 & 76 & 355 & 2,294 & 2,371 & 116 & 117 & 5,202 & 5,202 & 0.56 & 0.55 & 153 & 0.98 & 0.98 & 113 & 14 \\
\hline $350-355$ & 15.70 & 15.90 & 31 & 32 & 67 & 69 & 269 & 2,182 & 2,242 & 110 & 127 & 4,723 & 4,896 & 0.54 & 0.54 & 153 & 0.98 & 0.98 & 115 & 13 \\
\hline
\end{tabular}

* Abbreviations are the same as in preceding tables.

tered sodium reabsorbed averaged 0.65 (range 0.51 to 0.84 ) and was constant in each experiment before the interventions described below.

The effects of saline loading. The infusion of $600 \mathrm{ml}$ of isotonic saline resulted in an absolute decrease in the fraction of filtered sodium reabsorbed, which averaged -0.12 . This represented an average percentage change in fractional reabsorption $^{3}$ of $-19 \%$. The percentage decreases

${ }^{3}$ Percentage change in fractional reabsorption

$$
=\frac{\left(\frac{T_{\mathrm{Na}}}{\mathrm{F}_{\mathrm{Na}}}\right)_{2}-\left(\frac{\mathrm{T}_{\mathrm{Na}}}{\mathrm{F}_{\mathrm{Na}}}\right)_{1}}{\left(\frac{\mathrm{T}_{\mathrm{Na}}}{\mathrm{F}_{\mathrm{Na}}}\right)_{1}} \times 100,
$$

in fractional reabsorption for all of these experiments are shown in Figure 1. In most experiments the infusion of saline resulted in absolute decreases in the rate of tubular reabsorption of sodium as the excretion of sodium increased more than the increased filtered load of sodium (Figure 2). Details of experiments with saline infusion are given in Tables I and III.

In three experiments after collections were made during the small infusion of saline $(600 \mathrm{ml}$

where $F_{\mathrm{Na}_{2}}=$ the rate of filtration of sodium (GFR $X$ plasma $_{\mathrm{Na}}$ ), and $\mathrm{T}_{\mathrm{Na}}=$ the rate of tubular reabsorption of sodium $\left(\mathrm{F}_{\mathrm{Na}}-\mathrm{U}_{\mathrm{Na}} \mathrm{V}\right) .1=$ control measurements, and 2 = experimental measurements. 


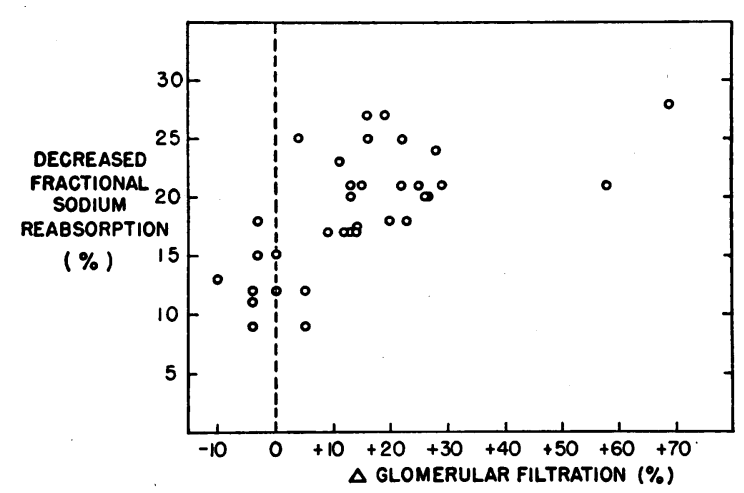

Fig. 1. Effects of SMall infusions of SALINE ON FRACTIONAL SODIUM REABSORPTION DURING BLOCKADE OF DISTAL REABSORPTION BY ETHACRYNIC ACID AND CHLOROTHIAZIDE. Points indicate the percentage change in fractional sodium reabsorption and glomerular filtration rate. The means of multiple uniform collections during hydropenia (drug infusion with replacement of urinary losses) and during saline infusion were used to calculate the changes. Fractional sodium reabsorption ranged from 0.56 to 0.81 during hydropenia and from 0.37 to 0.68 during the infusion of saline.

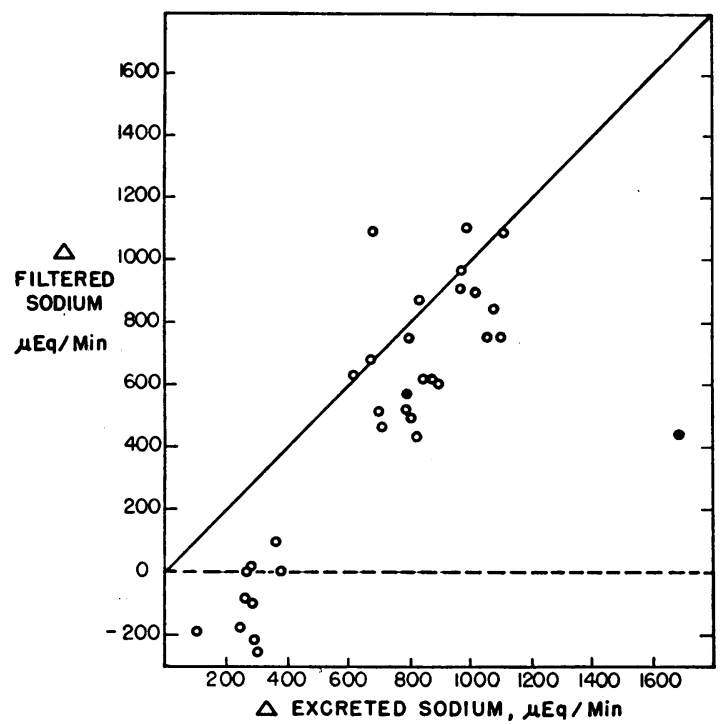

Fig. 2. Changes in filtered and exCreted SOdium RESULTING FROM THE INFUSION OF SALINE DURING DISTAL TUBULAR BLOCKADE WITH ETHACRYNIC ACID AND CHLOROTHIAZIDE. The solid circles represent experiments in which combined collections from the two kidneys were made, and all other points are changes in individual kidneys. The points represent means of multiple collections before and after the infusion of small (see Methods) volumes of saline. In most experiments the increased excretion of sodium was greater than the increased filtered load of sodium, as indicated by the number of points below the diagonal line, which represents unity.

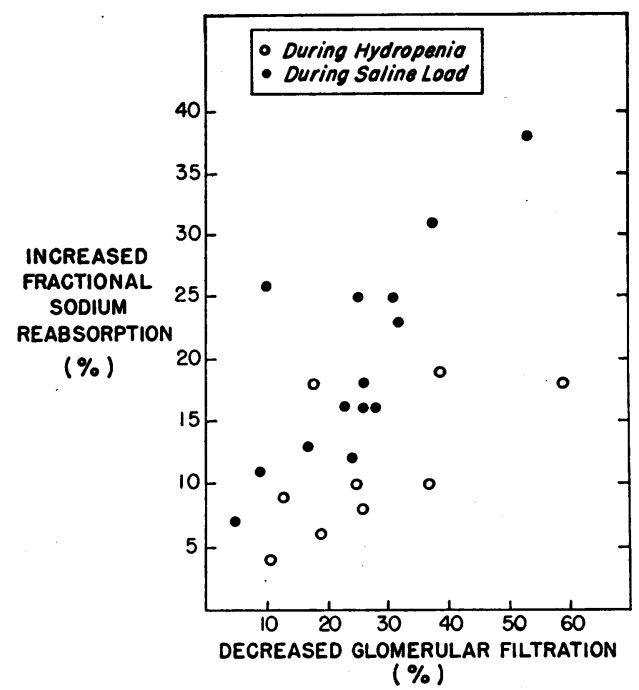

Fig. 3. EFFects OF REDUCED RENAL PERFUSION PRESSURE BY AORTIC CONSTRICTION ON GLOMERULAR FILTRATION AND FRACTIONAL SODIUM REABSORPTION DURING DISTAL BLOCKADE WITH ETHACRYNIC ACID AND CHLOROTHIAZIDE. Points are the changes in means of multiple collections before and after left renal perfusion pressure was reduced 14 to $55 \mathrm{~mm} \mathrm{Hg}$ by inter-renal aortic constriction. Solid circles are during the infusion of saline, and open circles are during hydropenia induced by drug infusion and replacement of urinary losses. In each experiment aortic constriction resulted in some increase in fractional sodium reabsorption as glomerular filtration was decreased.

followed by $10 \mathrm{ml}$ per minute), the animals received an additional $1,000 \mathrm{ml}$ at $50 \mathrm{ml}$ per minute, which was then continued at a rate equal to the increased rate of urine flow. In the six kidneys of these three experiments fractional sodium reabsorption was depressed an additional 7 to $13 \%$ by the second infusion of saline. This further decrease in fractional reabsorption was associated with an increased GFR in two and a decreased GFR in one of the experiments.

The effects of reduced GFR on sodium reabsorption. In 16 experiments both before and after saline loading, GFR was reduced 5 to $59 \%$ by constriction of the aorta above the left renal artery. In each of these experiments the fraction of filtered sodium reabsorbed increased (Figure 3 ). The percentage increase in fractional reabsorption appeared to be somewhat greater in the presence of saline loading than in the hydropenic state (replacement of urinary losses only), as shown in Figure 3. There was no evidence of autoregula- 
tion of RBF in these experiments, since RBF decreased in direct proportion to the reduction in perfusion pressure during aortic constriction, and renal vascular resistance remained constant or increased slightly in most of the experiments (Figure 4).

To determine whether the increased fractional reabsorption of sodium during aortic constriction was the result of the diminished GFR or the result of the diminished perfusion pressure, we decreased GFR at a constant or increased arterial pressure by the renal arterial infusion of norepinephrine in seven experiments. The relationship between the change in GFR and fractional reabsorption of sodium for these experiments is shown in Figure 5. The percentage change in fractional reabsorption of sodium in these studies ranged from -5 to +11 (average $+3 \%$ ) as GFR was reduced as much as $58 \%$. Arterial pressure during the renal arterial infusion of norepinephrine was changed from control by -5 to $+38 \mathrm{~mm} \mathrm{Hg}$. Thus, in contrast to the increased fractional reabsorption of sodium observed as GFR was decreased during reduced perfusion pressure (aortic constriction), similar reductions in GFR without reduced perfusion pressure resulted in little or no increase in the fractional reabsorption of sodium. Details of an experiment in which the effects of aortic constriction and the renal arterial infusion

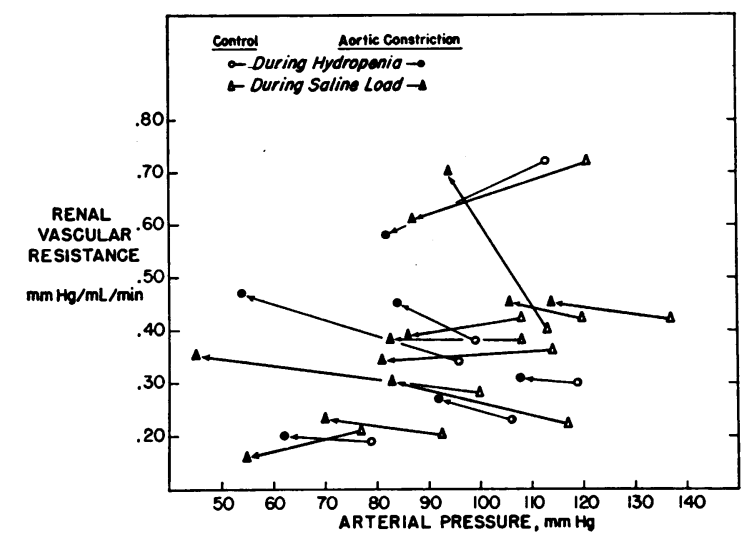

Fig. 4. EFFECTS OF AORTIC CONSTRICTION ON RENAL VASCULAR RESISTANCE AND RENAL PERFUSION PRESSURE DURING DISTAL TUBULAR BLOCKADE BY ETHACRYNIC ACID AND CHLOROTHIAzIDE. Both with and without saline infusion, renal vascular resistance usually did not decrease as perfusion pressure was reduced by aortic constriction, indicating a lack of autoregulation of renal blood flow during the drug infusions.

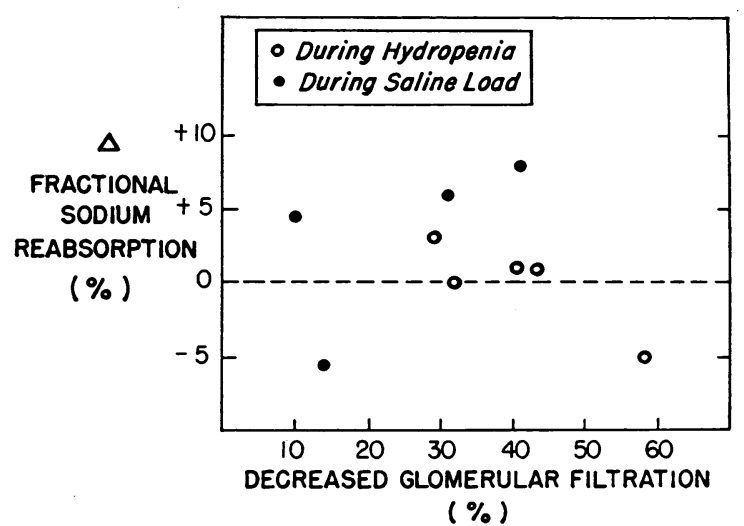

Fig. 5. EFFECTS OF RENAL ARTERIAL INFUSION OF NOREPINEPHRINE ON GLOMERULAR FILTRATION AND FRACTIONAL SODIUM REABSORPTION DURING DISTAL TUBULAR BLOCKADE BY ETHACRYNIC ACID AND CHLOROTHIAZIDE. Solid circles are during the infusion of saline, and open circles are during hydropenia. In these experiments glomerular filtration was reduced as much as $58 \%$ without a reduction in renal perfusion pressure. The fractional reabsorption of sodium changed little (average, $+3 \%$ ), in contrast with uniform increases in fractional reabsorption when glomerular filtration and perfusion pressure were reduced by aortic constriction (Figure 3 ).

of norepinephrine were compared are given in Table II.

The effects of renal vasodilatation and increased arterial pressure. In ten experiments unilateral renal vasodilatation was produced by the renal arterial infusion of acetylcholine. RBF increased an average of $12 \%$; GFR decreased by an average of $9 \%$. However, the fractional reabsorption of sodium was essentially unchanged during the renal arterial infusion of acetylcholine (range -6 to $+6 \%$ ). In ten experiments, which include seven of the studies during renal vasodilatation, arterial pressure was increased 5 to $89 \mathrm{~mm} \mathrm{Hg}$ by the intravenous infusion of angiotensin or norepinephrine. In these experiments the fractional reabsorption of sodium did not change in a consistent relationship to the changes in arterial pressure during the infusion of the pressor agents, but reabsorption decreased in eight of the ten, and this decreased reabsorption was independent of changes in GFR. The results of these studies are shown in Figure 6. Also shown in Figure 6 are the changes observed in the right kidney in the seven experiments in which arterial pressure was increased 5 to $38 \mathrm{~mm} \mathrm{Hg}$ during the infusion of norepinephrine into the left renal artery. 


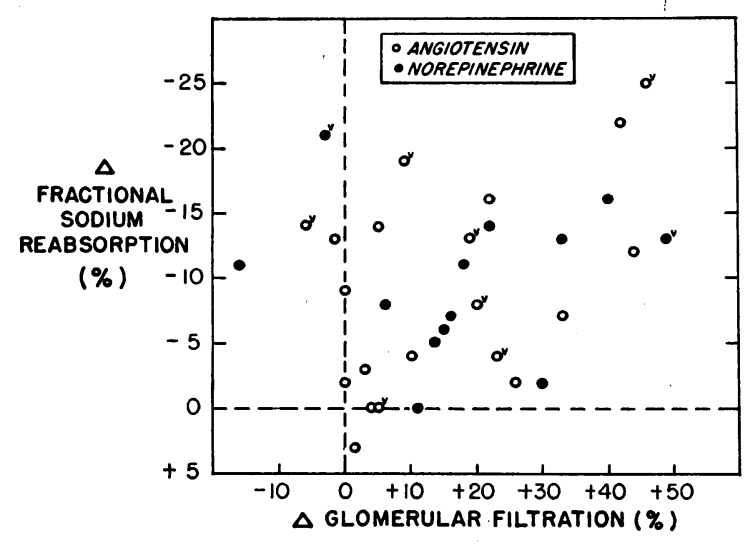

Fig. 6. EFFECTS OF INCREASED ARTERIAL PRESSURE ON FRACTIONAL SODIUM REABSORPTION DURING DISTAL TUBULAR BLOCKADE WITH ETHACRYNIC ACID AND CHLOROTHIAZIDE. Arterial pressure was increased 5 to $58 \mathrm{~mm} \mathrm{Hg}$ by the infusion of angiotensin (open circles) or norepinephrine (solid circles). Points indicated by $\mathrm{V}$ are vasodilated kidneys. The points represent changes in the means of multiple collections before and after the increased arterial pressure. Although fractional sodium reabsorption did not change significantly in all experiments, reabsorption was decreased in most of the studies, and this decreased fractional reabsorption was independent of the changes in glomerular filtration and occurred with or without renal vasodilatation. The figure includes measurements from the right kidneys in the experiments in which arterial pressure was elevated by the infusion of norepinephrine into the left renal artery (Figure 5).

The effects of infusions of albumin. In eight studies $30 \%$ bovine albumin was infused intravenously during saline loading. The purpose of these studies was to determine if increasing the plasma protein concentration would affect the fractional reabsorption of sodium, which had been depressed by the infusion of saline. The amount of albumin infused (75 g) was estimated to be sufficient to return the concentration of protein in plasma to values present before saline loading. Within 10 minutes after the infusion of $30 \%$ albumin was begun, the excretion of sodium began to decrease. The fractional reabsorption of sodium during the last two periods (10 minutes) of albumin infusion for all of these experiments is shown in Figure 7, and details of one experiment are given in Table III. In these experiments the infusion of $30 \%$ albumin resulted in decreases in GFR ranging from 6 to $33 \%$. RBF and arterial pressure were usually unchanged or increased. When the infusion of $30 \%$ albumin was discon- tinued and the saline-loading infusion continued, sodium excretion increased and the fractional reabsorption of sodium began to decrease (Table III). Plasma total protein concentrations were decreased an average of $28 \%$ during the infusion of saline, and during the final 10 minutes of the infusion of $30 \%$ albumin plasma total protein concentrations averaged $96 \%$ of presaline-loading control values.

To determine whether the increased fractional reabsorption of sodium during the infusion of $30 \%$ albumin related to the decreased GFR, in three experiments we infused norepinephrine into one renal artery to reduce GFR during saline loading before the infusion of albumin. The details of one of these studies are given in Table III. Reduction in GFR by norepinephrine did not increase fractional sodium reabsorption, in contrast to the striking increases in reabsorption during the infusion of the protein.

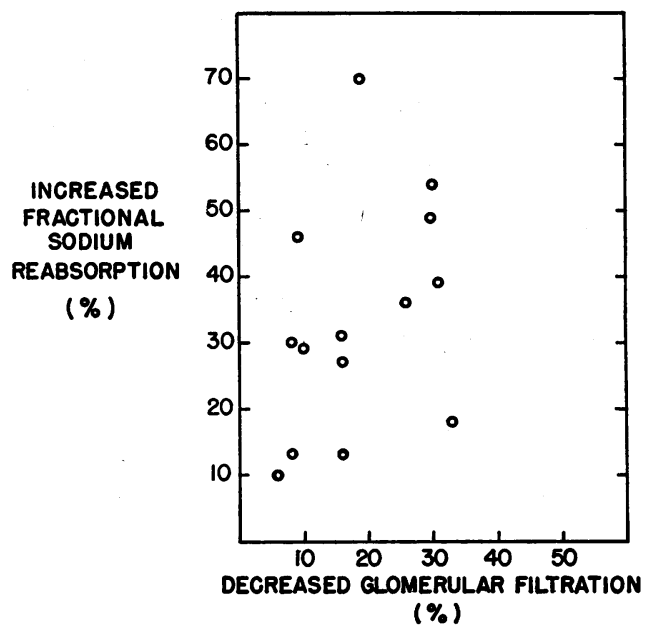

Fig. 7. EFfects OF INCREASED ONCOTIC PRESSURE ON THE FRACTIONAL REABSORPTION OF SODIUM DURING THE INFUSION OF SALINE IN THE PRESENCE OF DISTAL TUBULAR BLOCKADE WITH ETHACRYNIC ACID AND CHLOROTHIAZIDE. Points represent the changes in means of multiple uniform collections during saline infusion and the final two collections during the infusion of $250 \mathrm{ml}$ of $30 \mathrm{~g}$ per 100 $\mathrm{ml}$ bovine albumin. Fractional sodium reabsorption was increased strikingly by the infusion of protein, which returned plasma total protein concentrations to an average of $96 \%$ of the presaline infusion values. This increased fractional sodium reabsorption was independent of the extent to which glomerular filtration was decreased during the infusion of protein. Fractional sodium reabsorption ranged from 0.41 to 0.62 during the infusion of saline alone and from 0.62 to 0.82 at the completion of the infusion of protein. 
To examine whether expansion of the intravascular volume with "plasma-like" solutions affects fractional sodium reabsorption in a manner similar to the infusion of saline, we gave five animals a $300-$ or $400-\mathrm{ml}$ infusion of $6.5 \%$ bovine albumin in isotonic saline at $30 \mathrm{ml}$ per minute. This infusion was continued throughout the experiment at $5 \mathrm{ml}$ per minute. To minimize the possible effects of increased arterial pressure and increased RBF that occurred with these infusions of "plasma," we produced unilateral (left) renal vasodilatation by the renal arterial infusion of acetylcholine (40 $\mu \mathrm{g}$ per minute) before the infusion of plasma in two of the experiments. When arterial pressure increased (one of the five studies) after the infusion of plasma, collections were made and then the left renal perfusion pressure was reduced by aortic constriction to the same level present during the control collections (drug infusion with replacement of urinary losses) be-

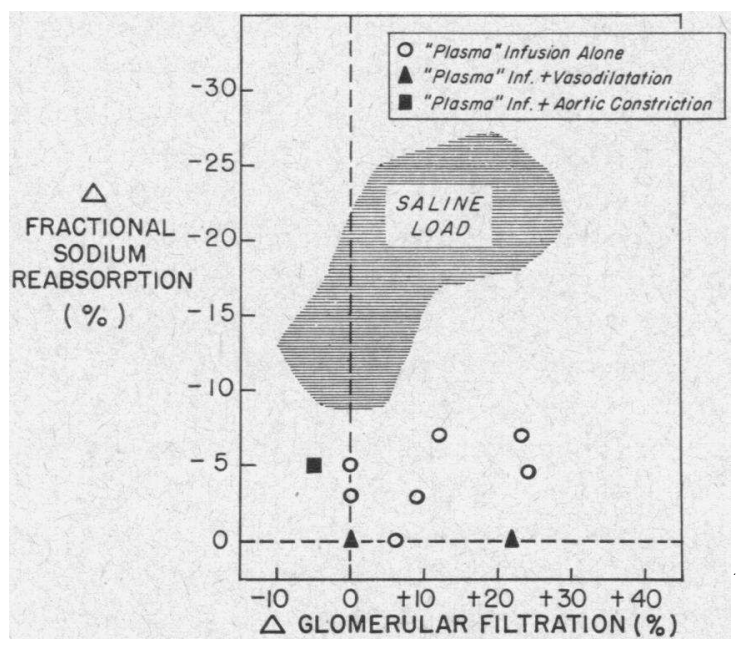

Fig. 8. EFFects of INFUsions of $6.5 \%$ PROTEIN SOLUTIONS ON FRACTIONAL REABSORPTION DURING DISTAL TUBULAR BLOCKADE BY ETHACRYNIC ACID AND CHLOROTHIAZIDE. Points are the changes in means of multiple collections during hydropenia and after the infusion of 600 to $800 \mathrm{ml}$ of "plasma" ( $6.5 \%$ bovine albumin in isotonic saline). In two experiments the left kidney was vasodilated by the renal arterial infusion of acetylcholine before the infusion of "plasma," and in one experiment left renal perfusion pressure was reduced by aortic constriction to the same level that was present before the infusion of plasma. All ten kidneys from the five studies are represented. The shaded area encloses all points (32 kidneys) observed through a similar range of change in glomerular filtration during the infusion of 600 to $1,000 \mathrm{ml}$ of saline (from Figure 1).

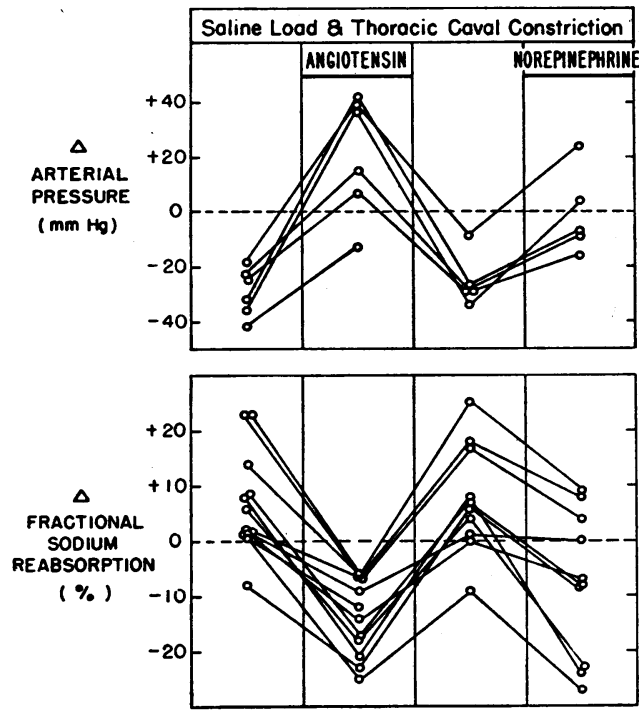

Fig. 9. EFFECT OF ACUTE THORACIC INFERIOR VENA CAVAL CONSTRICTION IN PREVENTING DEPRESSION OF FRACTIONAL SODIUM REABSORPTION DURING THE INFUSION OF SALINE AND REVERSAL OF THIS EFFECT BY INCREASED ARTERIAL PRESSURE. Changes are from mean hydropenic control values. As shown in the first column the infusion of saline in the presence of acute thoracic inferior vena caval constriction was associated with reduced arterial pressure, and fractional sodium reabsorption remained at or above hydropenic values in 11 of $12 \mathrm{ob}-$ servations. When arterial pressure was increased by the intravenous infusion of either angiotensin or norepinephrine, fractional sodium reabsorption decreased. In each of these studies, when arterial pressure was equal to or greater than initial control values, fractional sodium reabsorption decreased below hydropenic control values. Changes in the 12 kidneys of six experiments are shown.

fore the infusion of plasma. The effects of this infusion of plasma on fractional sodium reabsorption are summarized in Figure 8 . In all instances the change in reabsorption was distinctly less than the changes observed during saline infusions, whether or not arterial pressure was held constant and whether or not the kidney was previously vasodilated. After the infusion of 600 to $800 \mathrm{ml}$ of the $6.5 \%$ albumin solution, plasma total protein concentrations averaged $104 \%$ of control (range 95 to $119 \%$ ).

The effects of suprahepatic vena caval constriction. In six experiments after collections during the steady state diuretic infusion, the thoracic inferior vena cava was constricted to increase venous pressure to 15 to $28 \mathrm{~mm} \mathrm{Hg}$ by the device previously positioned through a thoracotomy. At 
the same time an intravenous infusion of isotonic Ringer's solution was begun at $30 \mathrm{ml}$ per minute and after 20 minutes slowed to $10 \mathrm{ml}$ per minute. One hour after the caval constriction, when the infusion of saline was begun, collections were continued. In these experiments the fractional reabsorption of sodium during the infusion of saline in the presence of caval constriction increased by an average of $7 \%$ (range -8 to $+23 \%$, Figure 9), in contrast to the decreased fractional reabsorption observed during saline infusions in the absence of caval constriction. The caval constriction resulted in reduced GFR, RBF, and arterial pressure. During caval constriction GFR was reduced 24 to $53 \%$ (average, $-39 \%$ ), RBF was reduced 29 to $59 \%$ (average, $-43 \%$ ), and arterial pressure decreased 23 to $42 \mathrm{~mm} \mathrm{Hg}$ (average, $-29 \mathrm{~mm} \mathrm{Hg}$ ). Arterial pressure was then elevated by the intravenous infusion of angiotensin to levels ranging from -13 to $+42 \mathrm{~mm} \mathrm{Hg}$ different from the preconstriction values. This resulted in increased GFR and RBF and decreased fractional reabsorption of sodium. In six kidneys of the six experiments the fractional reabsorption of sodium was decreased below control values despite continued depression of GFR when arterial pressure was increased during the infusion of angiotensin. In each experiment in which arterial pressure was elevated above the preloading and precaval constriction values, the fractional reabsorption of sodium was decreased below control values. Increasing arterial pressure with norepinephrine had the same qualitative effect of decreasing the fractional reabsorption of sodium. Thus, the effect of caval constriction of preventing a depression of fractional reabsorption of sodium during the infusion of saline was associated with decreased arterial pressure, and this inhibited depression of reabsorption was overcome when arterial pressure was increased. These experiments are summarized in Figure 9, and details of a single experiment are given in Table IV.

\section{Discussion}

The present study was designed to investigate by clearance techniques factors that may affect the proximal tubular reabsorption of sodium. The conclusions that the results of this study reflect changes in proximal reabsorption are dependent upon the following assumptions. 1) Ethacrynic acid and chlorothiazide together interfere with the major fraction of distal tubular reabsorption of sodium in the dog. This assumption appears justified, since clearance studies in the dog have demonstrated that ethacrynic acid abolishes the ability to elaborate a concentrated urine and reduces the capacity to excrete dilute urine, indicating an effect on sodium reabsorption in the loop of Henle (11). Chlorothiazide reduces diluting capacity but does not affect concentrating capacity, indicating an effect on sodium reabsorption beyond the loop of Henle (12). Together the two agents almost abolish diluting capacity (11), and in the present study the two drugs resulted in the excretion of about $35 \%$ of the glomerular filtrate in the hydropenic dog. Since micropuncture studies have demonstrated that dilution is totally a distal tubular phenomenon $(13,19,20)$ and that in the dog about $65 \%$ of the filtrate may be reabsorbed proximally (13), these latter observations from clearance studies are consistent with the view that the two agents together could abolish most of the reabsorption of sodium beyond the proximal nephron. 2) The agents should have no important effect on net reabsorption by the proximal nephron. Although an effect of diuretic agents to decrease proximal reabsorption may be masked by secondary changes in hydration or tubular volume (21), Dirks, Cirksena, and Berliner found no net effect of either ethacrynic acid or chlorothiazide on fractional reabsorption in the proximal tubule of the $\operatorname{dog}(14)$. 3) The maneuvers being studied should not in themselves alter the absolute effect of the agents on sodium reabsorption by the distal tubule. Although this possibility cannot be ruled out by the present studies, there is no indication that this is the case. Even when urine flow and the excretion of sodium were markedly reduced by some of the experimental procedures, urine remained virtually isotonic in the presence of increased fractional reabsorption of sodium, providing no evidence that this increased reabsorption occurred in the distal nephron. The possibility cannot be ruled out that in the presence of the diuretics significant distal isotonic reabsorption continued and could have become a larger fraction of the filtered load of sodium when distal delivery was diminished by some of the experimental procedures. If so, over- 
all fractional reabsorption could be increased without a change in proximal fractional reabsorption as distal delivery was diminished. However, it appears unlikely that this was the case in the present studies, since absolute increases in reabsorption were produced by hyperoncotic albumin in some experiments (Table III, Figure 7), and fractional reabsorption was not increased during arterial infusions of norepinephrine, despite very large decreases in GFR and distal delivery (Tables II and III, Figure 5). Likewise, residual distal reabsorption in the presence of the diuretics could be depressed by some of the experimental procedures (saline loading, increased arterial pressure) and could account in part for the over-all depression of fractional reabsorption. Although the present studies do not rule out the possibility that these maneuvers normally would depress distal reabsorption, it is unlikely that the large depressions in fractional reabsorption produced by saline loading and systemic angiotensin or norepinephrine could be due to what must be a very limited distal reabsorption in the presence of the diuretic agents. Therefore, whether or not distal reabsorption normally would be affected by the maneuvers studied, we can conclude that under the conditions of the present study, the changes observed occurred primarily in the proximal tubule. 4) The presence of the agents should not interfere with the independent effects of other factors on proximal tubular reabsorption. If the foregoing assumptions are correct, then it follows that any additional changes in tubular reabsorption are attributable to changes in proximal reabsorption independent of the action of the drugs. This should be true even though the agents may be exerting an inapparent effect on proximal reabsorption (21). In addition to the above considerations, changes in the reabsorption and excretion of sodium could relate to inverse changes in the reabsorption and excretion of potassium, which may occur in the distal nephron independent of the action of ethacrynic acid and chlorothiazide. However, in the present studies the relationship between the excretion of sodium and the excretion of potassium remained constant, and in none of the experiments were the fractional changes in sodium excretion due to inverse changes in the excretion of potassium.

In view of the foregoing considerations it ap- pears likely that the changes in both absolute and fractional reabsorption of sodium that occur in the presence of the combined diuretic infusions were related to changes occurring predominantly in the proximal tubule. If so, then the present studies demonstrate that several factors may independently affect proximal tubular reabsorption of sodium. The infusion of relatively small volumes of saline resulted in absolute decreases in "proximal" reabsorption. The decreases in proximal reabsorption of sodium resulting from these small infusions of saline averaged $-19 \% .^{4}$ Thus, the present studies are consistent with the view that the depressions of proximal tubular reabsorption in the dog that result from the infusion of saline as indicated by micropuncture of superficial nephrons (6) are qualitatively and probably quantitatively representative of the total nephron population. In three of the present studies, when an additional rapid infusion of saline was superimposed on the smaller saline load, further depressions in proximal fractional sodium reabsorption occurred; this change was independent of changes in GFR in one of the three studies. This suggests that the greater natriuretic effect of large and rapid saline infusions (5) as compared to smaller infusions $(1,2,6)$ is the result of a greater depression of proximal reabsorption.

The present studies indicate that a reduction in renal hemodynamics produced by aortic constriction may be associated with increased fractional reabsorption in the proximal nephron. This observation is in contrast to the findings by micropuncture of Dirks and co-workers (6), who observed a constant fractional reabsorption in the proximal nephron when renal arterial constriction was used to reduce GFR. However, our observation that aortic constriction increases the fractional reabsorption of sodium is in agreement with other reports that reduced renal perfu-

4 This average percentage change observed in the present studies is in reasonably good agreement with the average of $32 \%$ decrease in proximal tubular reabsorption during saline infusion in the dog reported by Dirks and associates (6) on the basis of re-collection by micropuncture at random sites along superficial proximal convolutions. However, the quantitative significance of this change in the present studies is not clear, since under the conditions of our studies the vascular and tubular effects of the diuretic agents could alter the response of the proximal nephron to the other factors studied. 
sion pressure may result in absolute increases in tubular reabsorption of sodium during saline (5) and mannitol (22) diuresis. In previous studies from our laboratory we suggested that the tubular reabsorption of sodium may relate in some way to the extent to which perfusion pressure is transmitted along the intrarenal circulation (9). In the normal kidney a reduction in perfusion pressure by aortic or renal arterial constriction is accompanied by reduced renal vascular resistance as the result of autoregulation. Such autoregulation could maintain a relatively constant hydrostatic pressure at distal portions of the renal circulation, despite the changes in renal arterial pressure. In support of this view are the observations of Thurau and Wober, who observed constant peritubular capillary pressures over a wide range of arterial pressures (23). In the present studies the combination of ethacrynic acid and chlorothiazide resulted in profound renal vasodilatation as RBF increased strikingly in the presence of reduced arterial pressure. Furthermore, in the present studies autoregulation was apparently abolished during the infusion of the diuretics, since renal vascular resistance did not decrease as perfusion pressure was reduced by aortic constriction. If, as previously suggested, transmission of pressure along the renal circulation is a factor that affects the reabsorption of sodium, then reabsorption should change readily in response to changes in perfusion pressure in the absence of autoregulation, as was the case in these studies. Consistent with this view are the observations that proximal fractional reabsorption of sodium was not decreased when GFR was reduced in the presence of unchanged or increased arterial pressure by the renal arterial infusion of norepinephrine. Since norepinephrine results in postcapillary, as well as precapillary, constriction (24), the reductions in GFR and renal blood flow produced by the infusions of norepinephrine could be associated with a higher capillary hydrostatic pressure than that present with similar reductions in these hemodynamics produced by aortic constriction. The filtration fraction remained constant during aortic constriction (Tables I and II), but increased during the renal arterial infusion of norepinephrine (Tables II and III). This suggests that during aortic constriction pressure and flow were uniformly reduced throughout the renal circulation. Although the increased filtration fraction during the arterial infusion of norepinephrine could be due to relatively greater efferent arteriolar constriction, such a change could be explained equally well by a combination of afferent and postcapillary constriction. These interpretations support the concept that the increased fractional reabsorption of sodium observed in these studies during aortic constriction was related to the reduced perfusion pressure and not to the reduction of GFR. Also, when arterial pressure was elevated in "hydropenic" animals (infusion of diuretics and replacement of urinary losses), fractional sodium reabsorption usually decreased; this change was independent of changes in glomerular filtration rate. It is not surprising that renal vasodilatation alone did not decrease fractional sodium reabsorption [in contrast to the previously reported effects of renal vasodilatation (15)], since profound vasodilatation was already present as a result of the diuretic agents alone. These observations strengthen the suggestions that renal perfusion pressure may be a determinant of the tubular reabsorption of sodium (9, $25,26)$, and under the conditions of the present studies this effect of pressure appears to be manifested in the proximal nephron.

We suggested, on the basis of previous studies from our laboratory, that the effect of perfusion pressure on the reabsorption of sodium may depend on a change in capillary hydrostatic pressure, which in turn could alter the renal interstitial volume (9). If so, then factors other than capillary hydrostatic pressure that should alter interstitial volume also should result in predictable changes in the reabsorption of sodium. It has been known for some time that infusions of hyperoncotic albumin may decrease the excretion of sodium in man (27-29), and that such infusions may not increase sodium excretion in the dog despite the associated expansion of the vascular volume (30). In the present studies the infusion of $30 \%$ albumin during saline loading resulted in marked increases in proximal fractional reabsorption of sodium, and in some cases absolute increases in the reabsorption of sodium. This effect of hyperoncotic albumin of increasing the reabsorption of sodium, which was previously depressed by the infusion of saline, was independent of changes in GFR and occurred with no decrease 
in $\mathrm{RBF}$ or arterial pressure. These observations are consistent with the interpretation that proximal reabsorption relates in some inverse manner to the renal interstitial volume. Since the rate of proximal tubular reabsorption may relate in some direct manner to tubular distension $(31,32)$, an inverse relationship between interstitial volume and proximal reabsorption could be mediated by changes in tubular volume. The distribution of volume between the capillary and interstitium should be determined according to "Starling forces." It seems likely that in the kidney the major source of interstitial volume is the tubular reabsorbed material, and the rate at which this volume is removed by the blood should be determined by the relationship between hydrostatic and osmotic (protein) pressures across the capillary wall. Thus, either increases in capillary hydrostatic pressure or decreases in plasma oncotic pressure could result in a relative shift of volume from capillary to interstitium as the removal of tubular reabsorbed material is slowed. The kidney has limited distensibility, and a decreased uptake of volume by the capillary may not reduce the intravascular volume so long as vascular resistance and perfusion pressure are constant. Therefore, an expansion of the interstitial volume due to decreased removal of reabsorbed material could result in a decrease in the tubular volume. However, any increase in interstitial volume resulting from decreased plasma oncotic pressure should be self-limited by a rise in pericapillary hydrostatic pressure as the extravascular volume increases. Thus, at lowered plasma oncotic pressure a new steady state could be achieved with an increased interstitial volume and pressure, a reduced volume of reabsorbed material due to tubular collapse, and an equally reduced rate of removal by blood of the tubular reabsorbed material. With increased plasma oncotic pressure or reduced capillary hydrostatic pressure an opposite series of changes could occur as the uptake by blood of interstitial volume increased. The resulting decreased interstitial volume and pressure could permit tubular distension (especially if GFR were constant) and thereby increase tubular reabsorption to equal the increased uptake of interstitial volume by blood. Such a mechanism whereby capillary pressure via changes in interstitial volume could play an important role in determining sodium reab- sorption and excretion remains unproved, but it could account for the effects of oncotic pressure, vasodilatation (15), and arterial pressure (9) on sodium reabsorption.

The possibility cannot be ruled out that the infusion of bovine albumin in the dog may have some "toxic" effect that resulted in the present findings, but there is no reason to favor such a conclusion. The observations by others that infusions of isooncotic plasma-like solutions depress the tubular reabsorption of sodium $(1,2)$ are not inconsistent with the present findings that hyperoncotic solutions of albumin increase proximal reabsorption. Since the infusion of plasma-like solutions may result in marked renal vasodilatation as well as increased arterial pressure (33), capillary pressure and interstitial volume could be increased during the infusion of iso-oncotic solutions; therefore, such studies $(1,2)$ do not provide conclusive evidence against an inverse relationship between interstitial volume and the reabsorption of sodium. Furthermore, in the present studies when animals were infused with relatively large volumes of an iso-oncotic albumin solution, whether or not renal perfusion pressure was kept constant, little or no depression in proximal reabsorption resulted. This failure of infusions of plasma to depress the reabsorption of sodium under the conditions of the present studies, in contrast to studies by others $(1,2)$, may relate to the fact that the infusion of ethacrynic acid and chlorothiazide produced striking renal vasodilatation, and any additional vasodilatation resulting from the infusion of plasma has little additional effect on reabsorption. Also, arterial pressure usually did not increase during infusions of iso-oncotic albumin. Therefore, the major change produced by these infusions was expansion of the vascular volume, and this had little or no effect on sodium reabsorption, even though GFR was increased in some of these studies. This conclusion suggests that the mechanism whereby the infusions of saline depress proximal reabsorption under the conditions of the present studies may be due largely to decreases in plasma oncotic pressure; this interpretation is supported by the observations that hyperoncotic albumin infusion reversed the saline-induced depression of fractional sodium reabsorption.

The present studies were extended to determine whether an effect on proximal tubular reabsorp- 
tion could be demonstrated during constriction of the thoracic inferior vena cava. This maneuver is known to result in the chronic retention of sodium and the accumulation of ascites (7), an inhibited or absent natriuretic response to acute saline loading $(10,34)$, and a failure of saline infusions to depress proximal reabsorption (8).

In the present studies acute constriction of the thoracic inferior vena cava prevented a decrease in proximal reabsorption during the infusion of saline, as has been observed by micropuncture studies (8). In most experiments, proximal fractional reabsorption was greater during caval constriction than during hydropenia alone, despite the infusion of saline. This effect of vena caval constriction was associated with decreased arterial pressure, as well as with decreased GFR and RBF. However, since reduced GFR and $\mathrm{RBF}$ without reduced arterial pressure during the renal arterial infusion of norepinephrine was not associated with increased proximal fractional reabsorption, we conclude that the decreased GFR and $\mathrm{RBF}$ per se during caval constriction are not the mechanism that inhibits the depressing of the fractional reabsorption of sodium by saline infusion. In support of the view that the reduced arterial pressure may be the important factor that limited the sodium reabsorption-depressing effect of saline loading are the striking effects of pressor infusions of either angiotensin or norepinephrine during caval constriction. In each experiment, during constriction of the thoracic inferior vena cava, when arterial pressure was increased to or above the preconstriction levels, proximal fractional reabsorption of sodium was promptly decreased despite the continued presence of caval constriction. In some experiments this effect of pressor agents of decreasing reabsorption in the presence of caval constriction occurred with filtration rates no greater than during hydropenic control periods. Other studies from our laboratory demonstrated that the inhibited response to saline loading that results from both acute and chronic constriction of the thoracic inferior vena cava may be overcome by increased arterial pressure in the presence of renal vasodilatation (10). The present observations suggest that this effect of increased arterial pressure of overcoming this retention of sodium during caval constriction is a proximal tubular phenomenon. Under the con- ditions of these studies the increased proximal reabsorption associated with acute thoracic inferior vena caval constriction appears to be largely the result of reduced arterial pressure.

In the present studies renal vasodilatation alone with acetylcholine had no effect on the fractional reabsorption of sodium and also was unnecessary for the effect of increased arterial pressure of depressing proximal reabsorption in the normal animal and during acute caval constriction. Since infusion of the diuretic agents alone results in profound renal vasodilatation, it may be unnecessary to produce further vasodilatation to permit depression of the reabsorption of sodium by increased arterial pressure. Consistent with this interpretation are other observations that renal vasodilatation alone increases the excretion of sodium when renal blood flow is relatively low (high renal vascular resistance), but in the presence of low renal vascular resistance during saline or mannitol diuresis further renal vasodilatation has no additional effect of increasing the excretion of sodium (15).

\section{Summary}

In the present studies we took advantage of the knowlegge that ethacrynic acid and chlorothiazide have separate and additive effects to interfere with the reabsorption of sodium in the distal nephron, that together they appear to block the major fraction of the distal tubular reabsorption of sodium, and that neither of them may have any net effect on proximal tubular reabsorption of sodium. During steady state infusions of the two agents and replacements of urinary losses, we invoked several different maneuvers to study factors that may influence proximal tubular reabsorption of sodium.

Infusions of saline resulted in both absolute and fractional decreases in "proximal" reabsorption, and the changes were qualitatively similar to the changes reported during saline loading for superficial cortical nephrons in the dog. Reduced perfusion pressure but not reduced glomerular filtration rate per se increased proximal fractional reabsorption of sodium. When arterial pressure was increased with either angiotensin or norepinephrine, proximal fractional reabsorption was usually decreased, independent of changes in 
glomerular filtration rate. During saline loading with depressed proximal reabsorption, infusions of hyperoncotic albumin strikingly increased the fractional reabsorption of sodium. Infusions of iso-oncotic "plasma-like" solutions had minimal effects on proximal reabsorption, despite marked expansion of the vascular volume. These observations are interpreted as indicating that the renal interstitial volume may be a factor inversely related to proximal tubular reabsorption, and that both capillary hydrostatic and plasma oncotic pressures may affect this mechanism.

Acute constriction of the thoracic inferior vena cava prevented a depression of proximal fractional reabsorption during the infusion of saline, as has been observed in micropuncture studies. This inhibited depression of proximal reabsorption was associated with decreased arterial pressure as well as decreased renal hemodynamics. When arterial pressure was increased to control levels or above by the infusion of norepinephrine or angiotensin, proximal fractional reabsorption decreased, indicating that this hemodynamically induced increased excretion of sodium in the presence of thoracic inferior vena caval constriction is a proximal phenomenon. The latter observations support the view that hemodynamically determined increases in proximal tubular reabsorption of sodium may play a role in the pathogenesis of such experimentally produced retention of sodium.

\section{Acknowledgments}

We are indebted to Helen Martin and Susan Howard for assistance with these studies.

\section{References}

1. De Wardener, H. E., I. H. Mills, W. F. Clapham, and C. J. Hayter. Studies on the efferent mechanism of the sodium diuresis which follows the administration of intravenous saline in the dog. Clin. Sci. 1961, 21, 249.

2. Levinsky, N. G., and R. C. Lalone. The mechanism of sodium diuresis after saline infusion in the dog. J. clin. Invest. 1963, 42, 1261.

3. Rector, F. C., Jr., G. Van Giesen, F. Kiil, and D. W. Seldin. Influence of expansion of extracellular volume on tubular reabsorption of sodium independent of changes in glomerular filtration rate and aldosterone activity. J. clin. Invest. 1964, 43, 341.

4. Earley, L. E., and R. M. Friedler. Observations on the mechanism of decreased tubular reabsorption of sodium and water during saline loading. J. clin. Invest. 1964, 43, 1928.

5. Earley, L. E., and R. M. Friedler. Changes in renal blood flow and possibly the intrarenal distribution of blood during the natriuresis accompanying saline loading in the dog. J. clin. Invest. 1965, 44, 929.

6. Dirks, J. H., W. J. Cirksena, and R. W. Berliner. The effect of saline infusion on sodium reabsorption by the proximal tubule of the dog. J. clin. Invest. 1965, 44, 1160.

7. Davis, J. O., D. S. Howell, and J. L. Southworth. Mechanisms of fluid and electrolyte retention in experimental preparations in dogs. III. Effect of adrenalectomy and subsequent desoxycorticosterone acetate administration on ascites formation. Circulat. Res. 1953, 1, 260.

8. Cirksena, W. J., J. H. Dirks, and R. W. Berliner. Effect of thoracic cava obstruction on response of proximal tubule sodium reabsorption to saline infusion. J. clin. Invest. 1966, 45, 179.

9. Earley, L. E., and R. M. Friedler. The effects of combined renal vasodilatation and pressor agents on renal hemodynamics and the tubular reabsorption of sodium. J. clin. Invest. 1966, 45, 542.

10. Friedler, R. M., L. J. Belleau, J. A. Martino, and L. E. Earley. Hemodynamically induced sodium excretion in dogs with sodium retention resulting from constriction of the thoracic inferior vena cava. In preparation.

11. Earley, L. E., and R. M. Friedler. Renal tubular effects of ethacrynic acid. J. clin. Invest. 1964, 43, 1495.

12. Earley, L. E., M. Kahn, and J. Orloff. The effects of infusions of chlorothiazide on urinary dilution and concentration in the dog. J. clin. Invest. 1961, 40, 857.

13. Clapp, J. R., J. F. Watson, and R. W. Berliner. Osmolality, bicarbonate concentration, and water reabsorption in proximal tubule of the dog nephron. Amer. J. Physiol. 1963, 205, 273.

14. Dirks, J. H., W. J. Cirksena, and R. W. Berliner. Micropuncture study on the effect of various diuretics on sodium reabsorption by the proximal tubule of the dog (abstract). Clin. Res. 1965, 13, 553.

15. Earley, L. E., and R. M. Friedler. Studies on the mechanism of natriuresis accompanying increased renal blood flow and its role in the renal response to extracellular volume expansion. J. clin. Invest. 1965, 44, 1857.

16. Gornall, A. G., C. J. Bardawill, and M. M. David. Determination of serum proteins by means of the biuret reaction. J. biol. Chem. 1949, 177, 751.

17. Wolf, A. V. Total renal blood flow at any urine flow or extraction fraction (abstract). Amer. J. Physiol. 1941, 133, 496.

18. Beyer, K. H. The mechanism of action of chlorothiazide. Ann. N. Y. Acad. Sci. 1958, 71, 363. 
19. Wirz, H. The location of antidiuretic action in the mammalian kidney in The Neurohypophysis. Proceedings of the 8th Symposium of the Colston Research Society, H. Heller, Ed. New York, Academic Press, 1957, p. 157.

20. Gottschalk, C. W., and M. Mylle. Micropuncture study of the mammalian urinary concentrating mechanism: evidence for the countercurrent hypothesis. Amer. J. Physiol. 1959, 196, 927.

21. Rector, F. C., Jr., F. P. Brunner, and D. W. Seldin. Pitfalls in the use of micropuncture for the localization of diuretic action. Ann. N. Y. Acad. Sci. In press.

22. Stein, R. M., R. G. Abramson, D. D. Bercovitch, and M. F. Levitt. Effects of unilateral renal arterial constriction on tubular reabsorption of sodium and water during an osmotic diuresis. J. clin. Invest. 1965, 44, 1720.

23. Thurau, K., and E. Wober. Zur Lokalisation der autoregulativen Widerstandsänderungen in der Niere. Pflügers Arch. ges. Physiol. 1962, 274, 553.

24. Cohn, J. N. Relationship of plasma volume changes to resistance and capacitance vessel effects of sympathomimetic amines and angiotensin in man. Clin. Sci. 1966, 30, 267.

25. Selkurt, E. E. Effect of pulse pressure and mean arterial pressure modification on renal hemodynamics and electrolyte and water excretion. Circulation 1951, 4, 541.

26. McDonald, S. J., and H. E. de Wardener. The relationship between the renal arterial perfusion pressure and the increase in sodium excretion which occurs during an infusion of saline. Nephron $1965,2,1$.

27. Goodyer, A. V. N., E. R. Peterson, and A. S. Relman. Some effects of albumin infusions on renal function and electrolyte excretion in normal man. J. appl. Physiol. 1949, 1, 671.

28. Welt, L. G., and J. Orloff. The effects of an increase in plasma volume on the metabolism and excretion of water and electrolytes by normal subjects. J. clin. Invest. 1951, 30, 751.

29. Petersdorf, R. G., and L. G. Welt. The effect of an infusion of hyperoncotic albumin on the excretion of water and solutes. J. clin. Invest. 1953, 32, 283.

30. Orloff, J., and W. D. Blake. Effects of concentrated salt-poor human albumin on metabolism and excretion of water and electrolytes in dogs. Amer. J. Physiol. 1951, 164, 167.

31. Gertz, K. H. Transtubuläre Natriumchloridflüsse und Permeabilität für Nichtelektrolyte im proximalen und distalen Konvolut der Rattenniere. Pflügers Arch. ges. Physiol. 1963, 276, 336.

32. Rector, F. C., Jr., F. P. Brunner, and D. W. Seldin. Mechanism of glomerulotubular balance. I. Effect of aortic constriction and elevated ureteropelvic pressure on glomerular filtration rate, fractional reabsorption, transit time, and tubular size in the proximal tubule of the rat. J. clin. Invest. 1966, 45, 590.

33. Martino, J. A., and L. E. Earley. Unpublished observations.

34. Levinsky, N. G., and R. C. Lalone. Sodium excretion during acute saline loading in dogs with vena caval constriction. J. clin. Invest. 1965, 44, 565 .

\section{SPECIAL NOTICE TO SUBSCRIBERS}

Post Offices will no longer forward the Journal when you move.

Please notify The Journal of Clinical Investigation, Business Office, 10 Stoughton Street, Boston, Mass. 02118, at once when you have a change of address, and do not omit the $\mathrm{Zip}$ Code number. 